\title{
Auditory Speech Perception Tests in Relation to the Coding Strategy in Cochlear Implant
}

\author{
Aline Cristine Bazon ${ }^{1} \quad$ Erika Barioni Mantello ${ }^{1} \quad$ Alina Sanches Gonçales $^{1} \quad$ Myriam de Lima Isaac ${ }^{1}$ \\ Miguel Angelo Hyppolito ${ }^{1}$ Ana Cláudia Mirândola Barbosa Reis ${ }^{1}$ \\ ${ }^{1}$ Department of Ophthalmology, Otorhinolaryngology and Head and \\ Neck Surgery, Universidade de São Paulo, Ribeirão Preto, SP, Brazil \\ Int Arch Otorhinolaryngol 2016;20:254-260. \\ Address for correspondence Erika Barioni Mantello, MD, PhD, \\ Department of Ophthalmology, Otorhinolaryngology and Head and \\ Neck Surgery, Universidade de São Paulo, Ribeirão Preto Medical \\ School, Av. Bandeirantes 3600, Campus Ribeirão Preto, SP, Brazil \\ 14049-900 (e-mail: erikafga@yahoo.com.br).
}

\begin{abstract}
Keywords

- cochlear implants

- auditory perception

- deafness

- hearing loss
\end{abstract}

Introduction The objective of the evaluation of auditory perception of cochlear implant users is to determine how the acoustic signal is processed, leading to the recognition and understanding of sound.

Objective To investigate the differences in the process of auditory speech perception in individuals with postlingual hearing loss wearing a cochlear implant, using two different speech coding strategies, and to analyze speech perception and handicap perception in relation to the strategy used.

Methods This study is prospective cross-sectional cohort study of a descriptive character. We selected ten cochlear implant users that were characterized by hearing threshold by the application of speech perception tests and of the Hearing Handicap Inventory for Adults.

Results There was no significant difference when comparing the variables subject age, age at acquisition of hearing loss, etiology, time of hearing deprivation, time of cochlear implant use and mean hearing threshold with the cochlear implant with the shift in speech coding strategy. There was no relationship between lack of handicap perception and improvement in speech perception in both speech coding strategies used.

Conclusion There was no significant difference between the strategies evaluated and no relation was observed between them and the variables studied.

\section{Introduction}

Deafness can affect an individual during adult age, i.e., after the development of hearing function and the acquisition of speech and language skills. This deficiency renders an individual unable to hear environmental and warning sounds or that of the human voice. Furthermore, deafness does not permit vocal modulation, causing onés voice to be esthetically poor. The personal sound amplifier device is efficient for the treatment of several hearing deficiencies, but some patients are still unable to recognize words and sentences even with the use of a powerful hearing aid. ${ }^{1}$

received

April 23, 2015

accepted

June 2, 2015

published online

July 28, 2015
DOI http://dx.doi.org/

10.1055/s-0035-1559595. ISSN 1809-9777.
A promising aid for the improvement of sound perception by individuals with severe/profound hearing loss is the cochlear implant $(\mathrm{CI})$, which directly stimulates the auditory nerve by means of electrodes implanted in the cochlea, allowing the nerve to transmit these electric signals to the brain. The $\mathrm{Cl}$ consists of an external component and a surgically implanted internal component. ${ }^{1,2}$

Many studies have evaluated speech perception in users of the $\mathrm{CI}$ system based on different speech coding strategies available in the speech processor in different situations of hearing, silence, and noise. ${ }^{1-5}$ These assessments are mostly performed during limited time intervals in adolescent and/or

Copyright $\odot 2016$ by Thieme Publicações License terms Ltda, Rio de Janeiro, Brazil

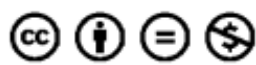


adult individuals, with a combination of speech perception tests and self-assessment questionnaires.

One study ${ }^{6}$ evaluated the role of temporal fine structure processing in tests of pitch perception, masking and speech perception for normal-hearing and hearing-impaired people. The complex broad band sounds are decomposed by auditory filters into a series of relatively narrow signals, each one of them considered to be a variation of storage, with placement in a temporal fine structure (TFS). Both the TFS and storage data are represented at the time of neural firing, although TFS information depends on the phase associated with the cycles of the wave stimulus. The $\mathrm{CI}$ devices currently available mainly allow the storage of information in different pitch ranges, a fact that may explain in part the Cís relatively low capacity to understand speech when background sounds are present.

Other studies have associated the strategies with the number of activated channels. ${ }^{7,8}$ The data did not permit relating a specific region of the cochlea to a better performance in speech perception. Nonetheless, 7 of the 12 patients tested obtained better performance when the 6 basal channels were activated. This suggests that, in partial insertions in which the electrodes do not reach the more apical region of the cochlea and stimulation occurs more intensely in the basal and medial regions, there may be utilization of auditory information. ${ }^{7}$ Riss et $\mathrm{al}^{8}$ investigated the correlation between time of use of the Opus speech processor and the speech coding strategy Fine Structure Processing (FSP). The results showed that the speech processor had a significant advantage in the signal/noise ratio ( $10 \mathrm{~dB}$ ) compared with the Tempo+ speech processor used for the Continuous Interleaved Strategy (CIS). In addition, the Opus speech processor has a broader pitch band and both factors (pitch band and speech coding strategy) possibly contributed to the differences in the scores of the speech perception tests (SPT).

The implantable $\mathrm{CI}$ unit is the interface for the transmission of electrical stimuli to the neurons of the spiral ganglion. These stimuli are processed by the external unit or speech processor, in which the sound is converted or processed into signals transmitted via radiofrequency to the internal unit, which in turn converts the signal into an electrical impulse. This impulse is then sent to the brain and interpreted as sound. ${ }^{9}$ This results in significant auditory sensations that can lead to the understanding of speech. The speech processing strategies use to achieve this objective vary according to the characteristics of the implant used and can be classified according to their properties. Most of the current implants are multichannel ones, with the sound that reaches the processor filtered into various pitch bands, each associated with a pair of electrodes. A pitch band and its electrodes are called "channels." Today, the most frequently used speech processing strategies differ in number of channels and in the speed of the stimulation for each channel.

Different speech coding strategies are available in Cochlear Corporation ${ }^{\circledR}$ devices (Advanced Combination Encoder - ACEand Continuous Interleaved Strategy - CIS - Centennial, USA) and in Medel ${ }^{\circ}$ devices (FSP strategy and Fine Structure 4 - FS4-strategy - Innsbruck, Austria).
The ACE strategy emphasizes the spectral and temporal clues of the acoustic signal. The device relies on a dynamic selection of the stimulated channels depending on the frequencies of greater or maximum amplitude of the pitch bands of the sound that reaches the processor. This strategy selects $6,8,12$ or 20 maxima from the signal spectrum and stimulates the corresponding channels at a rate ranging from 250 to 2400 pulses/second per channel. It incorporates high rates of stimulation and is currently considered the standard strategy for the use of Cochlear Corporation ${ }^{\circledR}$ devices. ${ }^{10}$

The CIS strategy stimulates multiple electrodes in a nonsimultaneous manner, although at a much higher rate of stimulation than that of the SPEAK strategy. In the CIS strategy, programming is performed by choosing 4-12 fixed channels always stimulated at each impulse. The rate of stimulation is 720 to $2400 \mathrm{~Hz}$. The CIS strategy gives priority to temporal information rather than spectral information and was developed to reduce channel interaction with the use of non-simultaneous channel stimulation. Biphasic pulses are delivered to the electrodes by non-simultaneous stimulation starting from the extraction of the acoustic signal (temporal information). ${ }^{10}$

The FSP strategy provides sequential stimulation of two adjacent electrodes, used to focus on the stimulation of additional neural fibers, providing better spectral resolution. Its low frequency channels ( 1 to 4 ) are also set to code both the envelope and the fine structure of the sound wave. For these apical channels, the high rate of fixed stimulation is replaced with continuous special stimulus sequences (CSSS), which are a series of special electrical pulses that carry the fine structure information, i.e., the number of CSSS channels and the pitch interval with the coding of fine structures that depend on the configurations of the patients parameters.

In the FS4 strategy, sound processing is quite similar to that of FSP, except that CSSS channels work in a constant manner, independent of the configurations of the patients parameters, i.e., there are four apical channels ( 1 to 4 ) working at an estimated rate of 6000 pulses/second per channel. This strategy is currently considered the standard for the use of Medel® devices. ${ }^{10}$

The considerations above stimulated our interest in studying the differences in the speech perception process in postlingual hearing-impaired adult individuals using CI systems involving four different speech-coding strategies available for speech processors.

The objectives of the present study were to determine the differences in the speech perception process between two speech coding strategies available in the device used by the patient, i.e., the habitual one (indicated on the occasion of activation) and a second one (an option after programming for the test), to analyze the results of the speech perception tests with the two different speech coding strategies, and to determine the perception of the handicap.

\section{Method}

This was a prospective cross-sectional cohort study of a descriptive character. The Research Ethics Committee of the 
institution involved has approved the research and registered it under number 9415/2010. All the participants provided their written informed consent forms to participate in this study, which the ethics committee then approved.

The study was conducted with 10 subjects of both genders, older than 18 years of age, users of a multichannel $\mathrm{CI}$. Inclusion criteria were the effective use of a $\mathrm{CI}$ for at least six months, the ability to recognize open set speech and a diagnosis of postlingual sensorineural hearing loss. Subjects with associated neurological and/or psychiatric impairment were excluded.

Eighty percent of the $\mathrm{CI}$ users wore a Cochlear Corporation ${ }^{\circledR}$ device (ACE as the habitual strategy and CIS as the second strategy) and $20 \%$ wore a MedEl ${ }^{\circledR}$ device (FSP as the habitual strategy and FS4 as the second strategy).

The following procedures were used for data collection: demographic characterization of the subjects based on their medical records, determination of hearing threshold in free field with the $\mathrm{CI}$, assessment of speech perception by means of a recognition of lists of monosyllabic and disyllabic words ${ }^{11}$ and lists of sentences, ${ }^{12}$ and application of the Hearing Handicap Inventory for Adults (HHIA) questionnaire ${ }^{13}$ to assess the perception of the change in coding strategy by means of directed questions.

The authors created maps for all the strategies and optimized based on the necessary changes for each individual. Then, authors assessed the subjects again according to the same protocol. The variations in strategies and the assessments occurred on the same day to determine whether there were differences and whether the subjects were able to perceive them during the application of the tests. After the data were obtained, the speech processors were programmed with the participantś preferred strategy.

The habitual strategy (i.e., the one indicated upon activation) was denoted Strategy 1, and the second strategy, an alternative to the habitual one after programming for the test, was denoted Strategy 2.
All speech perception tests were applied in a soundproof booth using an audiometer connected to an amplifier in free field and an acoustic box at $0^{\circ}$ azymuth at a fixed intensity of 70 dBNA, with the subject positioned at a distance of one meter from the loudspeaker.

For statistical analysis, the authors reviewed the data to synthesize a series of values of the same nature, permitting an overall view of variation, organizing and describing them in tables with descriptive measures. This analysis was performed using the PROC MEANS feature of the SAS ${ }^{\circledR} 9.0$ software (California, USA). ${ }^{14}$ The Student $t$-test for paired quantitative data was used to compare the strategies used and the hearing loss variables (subject's age, age at hearing loss, time of hearing deprivation, and mean auditory thresholds with the use of the $\mathrm{CI}$ ) to the speech perception tests. In this case, pairing is observed by obtaining the respective measurements in the same subject with the two strategies used. The study also relied on the Pearson correlation coefficient to quantitate the association between two variables.

\section{Results}

- Table 1 presents the characterization of the subjects regarding age and aspects related to hearing loss.

Regarding the strategies used, eight patients using the Cochlear Corporation ${ }^{\circledR}$ device used the ACE strategy as Strategy 1 , while two subjects using the $\mathrm{MedEl}^{\circledR}$ device used the FSP strategy as Strategy 1.

As for Strategy 2, the CIS strategy was introduced in the eight patients using the Cochlear Corporation ${ }^{\circledR}$ device, whereas the FS4 strategy was introduced in the two MedEl device users.

-Table 2 lists the results of the SPT in the two phases of assessment: the first, when the subjects used Strategy 1 (habitual) and, the second, using Strategy 2 (second strategy chosen after optimized mapping).

The results of the comparison between the SPT and Strategies 1 and 2 are listed in - Table 3 . Analysis of the three

Table 1 Data regarding hearing loss of the subjects studied $(\mathrm{N}=10)$

\begin{tabular}{|l|l|l|l|l|l|l|}
\hline Subjects & $\begin{array}{l}\text { Age } \\
\text { (months) }\end{array}$ & $\begin{array}{l}\text { Age at HL } \\
\text { (months) }\end{array}$ & $\begin{array}{l}\text { THL } \\
\text { (months) }\end{array}$ & $\begin{array}{l}\text { TUCl } \\
\text { (months) }\end{array}$ & $\begin{array}{l}\text { Mean thresholds } \\
\text { with the Cl (dBNA) }\end{array}$ & AR \\
\hline 1 & 468 & 96 & 216 & 20 & 28 & No \\
\hline 2 & 543 & 60 & 48 & 33 & 17 & Yes \\
\hline 3 & 367 & 108 & 36 & 79 & 25 & Yes \\
\hline 4 & 804 & 360 & 48 & 72 & 25 & Yes \\
\hline 5 & 355 & 72 & 24 & 55 & 27 & Yes \\
\hline 6 & 459 & 288 & 84 & 84 & 42 & No \\
\hline 7 & 504 & 144 & 24 & 48 & 23 & Yes \\
\hline 8 & 702 & 144 & 384 & 74 & 20 & Yes \\
\hline 9 & 282 & 168 & 36 & 19 & 39 & Yes \\
\hline 10 & 500 & 144 & 60 & 8 & 25 & Yes \\
\hline
\end{tabular}

Abbreviations: AR, auditory rehabilitation; $\mathrm{Cl}$, cochlear implant; $\mathrm{HL}$, hearing loss; THL, Time of hearing loss; TUCI, Time of use of the cochlear implant. 
Table 2 Results of the speech perception test (monosyllables, disyllables and sentences) with the use of Strategies 1 and 2

\begin{tabular}{|c|c|c|c|c|c|c|c|c|c|}
\hline \multirow[t]{2}{*}{ Strategy } & \multirow[t]{2}{*}{$\bar{n}$} & \multirow[t]{2}{*}{ Variable } & \multirow[t]{2}{*}{ Mean } & \multirow[t]{2}{*}{ SD } & \multicolumn{2}{|c|}{$95 \% \mathrm{Cl}$} & \multirow[t]{2}{*}{ Minimum } & \multirow[t]{2}{*}{ Median } & \multirow[t]{2}{*}{ Maximum } \\
\hline & & & & & $\mathrm{LL}$ & UL & & & \\
\hline \multirow[t]{3}{*}{1} & \multirow[t]{3}{*}{10} & Monosyllables & 0.55 & 0.03 & 0.52 & 0.57 & 0.52 & 0.54 & 0.60 \\
\hline & & Disyllables & 0.58 & 0.09 & 0.51 & 0.64 & 0.40 & 0.60 & 0.72 \\
\hline & & Sentences & 0.79 & 0.16 & 0.67 & 0.90 & 0.50 & 0.78 & 1.00 \\
\hline \multirow[t]{3}{*}{2} & \multirow[t]{3}{*}{10} & Monosyllables & 0.44 & 0.14 & 0.34 & 0.54 & 0.24 & 0.46 & 0.64 \\
\hline & & Disyllables & 0.52 & 0.12 & 0.44 & 0.61 & 0.32 & 0.54 & 0.68 \\
\hline & & Sentences & 0.69 & 0.25 & 0.51 & 0.87 & 0.12 & 0.74 & 0.94 \\
\hline
\end{tabular}

Abbreviations: Cl, confidence interval; LL, lower limit; n, number of subjects; SD, standard deviation; UL, upper limit.

SPT did not reveal significant differences, although the $p$ value for monosyllabic words was close to significance.

Additionally, we observed no significant difference when correlating SPT results using Strategies 1 and 2 with the following variables: current subject's age (months), subject's age at the time of acquisition of hearing loss, mean thresholds with the $\mathrm{CI}$, time of $\mathrm{CI}$ use, and time of hearing deprivation (-Table 4).

- Table 5 shows the speech perception strategies employed by the $\mathrm{CI}$ users at each assessment time. The final score obtained with the HHIA is reported as a percentage for each subject. Eight of the ten subjects obtained scores ranging from zero to $16 \%$, implying a lack of handicap perception. One subject obtained a score from 18 to $42 \%$, corresponding to a mild/moderate handicap perception, and only one subject presented severe handicap perception, with a score over $42 \%$.

\section{Discussion}

Studies have demonstrated the need to assess speech perception, with several investigations contributing to the adaptation and validation of SPT in different listening situations. In parallel, the development of the electronic devices used as hearing aids aimed at better utilization of residual hearing have contributed to an improved quality of speech perception in individuals with hearing deficiency.

All the subjects participating in the present study had postlingual hearing loss (one of the eligibility criteria), had mean hearing thresholds in the range of 20 to 42dBNA, and had received or were still receiving systematic hearing rehabilitation. In this study, we opted to determine whether CI users with postlingual hearing loss would be able to perceive changes in speech perception after changes in mapping over a short period, such as on the same day they appeared for follow-up during the program.

Analysis of the SPT results of the present sample did not reveal significant changes regarding the tests applied (monosyllabic and disyllabic words and sentences) between the two strategies used, nor did it show a correlation with the variables studied. Similar results have been reported in the literature when non-sensitized SPT are used, ${ }^{2,4,6}$ confirming that the variability in $\mathrm{CI}$ performance among the users is related to each systeḿs coding strategies for each user in particular.

Two of the ten participants completed data collection with the possibility of routinely using Strategy 2 , the strategy available in the device reported by the subject, to provide better perception after Strategy 1. One of them, Subject 1, opted to fix Strategy 2 as the habitual one after obtaining better SPT performance and reporting that it was better for listening (perception by the subject himself). The other subject (no. 6) was given the possibility of using one of the two programs (Strategy 1 and 2) by obtaining a similar performance with both, with the possibility of improved hearing perception after a period of acclimatization to Strategy 2 . However, this result did not persist over the three subsequent months and both patients requested a return to Strategy 1 (habitual), claiming that the difficulties in open set speech recognition had worsened with the new strategy. This confirmed literature data about the need for a process of acclimatization to the new forms of listening that would optimize the functioning of the auditory system after a change in acoustic information. ${ }^{2,15-18}$

Table 3 Results of the comparison of Strategies 1 and 2 regarding the speech perception tests used (monosyllables, disyllables and sentences)

\begin{tabular}{|l|l|l|l|l|}
\hline Comparison of Strategies 1 and 2 & Estimated difference & LL & UL & P value \\
\hline Monosyllables & 0.10 & 0.0015 & 0.2095 & 0.052 \\
\hline Disyllables & 0.05 & -0.0400 & 0.1464 & 0.24 \\
\hline Sentences & 0.09 & -0.0300 & 0.2200 & 0.13 \\
\hline
\end{tabular}

Abbreviations: LL, lower limit; UL, upper limit. 
Table 4 Correlation of speech perception test results with hearing loss data

\begin{tabular}{|l|l|l|l|l|l|}
\hline SPT and strategy used & Age & Age at $\mathrm{HL}$ & Mean hearing threshold & Time of hearing deprivation & Time of Cl use \\
\hline Mono_strat1 & -0.2980 & -0.2107 & 0.3619 & -0.4330 & 0.1675 \\
\hline $\mathrm{P}$ value & 0.4029 & 0.5590 & 0.3041 & 0.2112 & 0.6437 \\
\hline Mono_strat2 & 0.1122 & -0.1134 & 0.3262 & -0.1388 & -0.5537 \\
\hline $\mathrm{P}$ value & 0.7575 & 0.7550 & 0.3575 & 0.7020 & 0.0968 \\
\hline Disyll_strat1 & -0.5095 & 0.3771 & -0.1437 & -0.6280 & 0.1162 \\
\hline P value & 0.1325 & 0.2827 & 0.6920 & 0.0518 & 0.7492 \\
\hline Disyll_strat2 & -0.3600 & 0.1858 & -0.0138 & -0.1011 & -0.6309 \\
\hline p value & 0.3067 & 0.6072 & 0.9697 & 0.7811 & 0.0504 \\
\hline Sent_strat1 & -0.2477 & 0.3019 & -0.2088 & -0.3833 & 0.0462 \\
\hline P value & 0.4902 & 0.3965 & 0.5626 & 0.2741 & 0.8990 \\
\hline Sent_strat2 & -0.4371 & 0.2143 & 0.0353 & -0.6149 & -0.4400 \\
\hline P value & 0.2065 & 0.5521 & 0.9229 & 0.0585 & 0.2031 \\
\hline
\end{tabular}

Abbreviations: Cl, cochlear implant; disyll, disyllabic word; HL, hearing loss; Mono, monosyllabic word; sent, sentence; SPT, speech perception test; strat 2, strategy 2; strat1, strategy 1.

Carvalho ${ }^{19}$ stated that $\mathrm{CI}$ mapping and balancing should be performed periodically in adults and that mapping may change within the first six months since this is the period of adaptation to the electrical stimulus. After this period, mapping may be changed when the patient feels the need and for it and for better safety.

Current studies have confirmed the need to combine tests that will permit the professional to opt for the best conduct for the patient. In the present study, the subjective perception of these two individuals during the test were not confirmed (cross-check principle) with the results of the SPT and/or the questionnaire applied.

Statistical analysis did not reveal a significant difference between the SPT results obtained with Strategy 1 (habitual) and Strategy 2 (change after mapping), or regarding the remaining variables studied. Similar findings were reported by Riss et $\mathrm{al}^{8}$ which did not detect a significant advantage in the comparison of SPT using the FSP or CIS strategy, with the speech perception of the $\mathrm{Cl}$ users being similar with the use of the two strategies. Data regarding hearing loss also showed no correlation with SPT results or the strategies used.

Although no significant differences were noted between the two strategies for any of the variables studied, a qualitative analysis of the results for each subject revealed that two of them (subjects 4 and 10), who showed a better SPT performance and who had a time of hearing deprivation of less than five years, were under audiology follow-up (hearing rehabilitation) and had a mean auditory threshold of 25dBNA with the use of the $\mathrm{Cl}$.

Subjects 5 and 8 showed the worst performance in SPT, an intriguing fact for subject 5 who was in one of the best conditions for the group regarding the time of hearing

Table 5 Strategies used at each time of $\mathrm{Cl}$ user evaluation

\begin{tabular}{|l|l|l|l|l|l|}
\hline Subjects & Cl brand & Strategy $\mathbf{1}$ & Strategy $\mathbf{2}$ & Strategy preference & Strategy after $\mathbf{3}$ months \\
\hline 1 & MedEl & FSP & FS4 & FS4 & FSP \\
\hline 2 & Cochlea & ACE & CIS & ACE & ACE \\
\hline 3 & Cochlear & ACE & CIS & ACE & ACE \\
\hline 4 & Cochlear & ACE & CIS & ACE & ACE \\
\hline 5 & Cochlear & ACE & CIS & ACE & ACE \\
\hline 6 & Cochlear & ACE & CIS & CIS & ACE \\
\hline 7 & Cochlear & ACE & CIS & ACE & ACE \\
\hline 8 & Cochlear & ACE & CIS & ACE & ACE \\
\hline 9 & MedEl & FSP & FS4 & FSP & FSP \\
\hline 10 & Cochlear & ACE & CIS & ACE & ACE \\
\hline
\end{tabular}

Abbreviations: ACE, advanced combination encoder; $\mathrm{Cl}$, cochlear implant; CIS, continuous interleaved strategy; FS4, fine structure 4; FSP, fine structure processing. 
deprivation (two years) and who also had the lowest handicap perception in the group studied (a score of 8 ). Subject 8 showed poorer SPT results probably owing to meningitis as the etiology of hearing loss, in agreement with studies reporting a poorer SPT performance in adults with postmeningitis deafness. ${ }^{20,21}$

Another study ${ }^{3}$ reported that sentence recognition by $\mathrm{CI}$ users in the presence of silence and of noise improved with device time of use, a result that we did not observe in the present study in a significant manner. Tests that investigate speech recognition with competition (noise or speech) seem to be more sensitive for the identification of the benefits of processors and strategies. Some authors ${ }^{22}$ have discussed the need to expand the procedure for evaluation, with a more difficult degree of complexity of the auditory tasks, especially for users with a good speech recognition performance when using their processors and habitual strategies.

The mean thresholds observed in $\mathrm{CI}$ users in the present study was $27 \mathrm{~dB}$, in agreement with data reported by Santos et $\mathrm{al}^{4}$, who stated that, despite the different types of $\mathrm{CI}$, the audiometric thresholds did not exceed $40 \mathrm{~dB}$. The etiology most frequently detected was that of unknown cause (idiopathic), observed in $50 \%$ of the participants, a result that agrees with the study of Calhau et $\mathrm{al}^{23}$, who also observed deafness of idiopathic cause in $40 \%$ of their patients.

The investigation of the etiology (50\% idiopathic) is necessary to aid the process of evaluation in the presurgical phase and mainly the planning of treatment and the determination of the prognosis of intervention.

Some studies have demonstrated that, in some cases of deafness secondary to meningitis, implants do not yield results as satisfactory as those obtained in patients with deafness due to other etiologies. ${ }^{24}$ Another factor to be considered in these cases is ossification, commonly occurring in many patients after meningitis, with a negative influence resulting in a larger number of complications and of partial electrode insertion. ${ }^{25}$

The HHIA questionnaire applied to the subjects in the form of an interview revealed a lack of handicap perception in most subjects (eight), although, only one of the subjects evaluated showed improved speech perception regarding monosyllables, disyllables and sentences when switching strategies. The results of the present study agree in part with those reported by Lima, Aiello and Ferrari, ${ }^{26}$ who stated that the speech test (LRF) showed weak, albeit significant, positive correlations regarding handicap perception by $\mathrm{CI}$ users.

Based on the present results, it can be seen that the performance of speech perception may be more closely related to characteristics such as time of hearing deprivation, age of the $\mathrm{CI}$ user, time of acclimatization, (i.e., time needed for an individuals hearing system to reorganize and to start to effectively perceive the spectral information provided by the strategy indicated). It should be pointed out that the results of the rehabilitation process in $\mathrm{CI}$ users are directly related to other factors such as the individual characteristics of the users, their biopsychosocial aspects, their own and/or their family's involvement in the therapeutic process, the application of specialized audiology follow-up (hearing rehabilitation), and the etiology of the hearing loss. Thus, there should be further research on these factors to define their contribution to auditory performance with the use of speech coding strategies.

\section{Conclusion}

There was no significant difference between the strategies evaluated, nor were they related to the variables studied. However, after the application of the SPT, two subjects preferred the use of the second strategy (not habitual) on the occasion of the test and reported improved speech perception during the test, returning to their habitual strategy a short time later. This fact indicates the need for some time for acclimatization for a better perception of the benefits of the strategy used for speech perception.

\section{References}

1 Bento RF, Brito Neto R, Castilho AM, Gómez VG, Giorgi SB, Guedes MC. Resultados auditivos com o implante coclear multicanal em pacientes submetidos a cirurgia no Hospital das Clínicas da Faculdade de Medicina da Universidade de São Paulo. Rev Bras Otorrinolaringol 2004;70:632-637

2 Frederigue NB, Bevilacqua MC. Otimização da percepção da fala em deficientes auditivos usuários do sistema de implante coclear multicanal. Rev Bras Otorrinolaringol 2005;69:227-233

3 Nascimento IT, Bevilacqua MC. Avaliação da percepção da fala com ruído competitivo em adultos com implante coclear. Braz J Otorhinolaryngol 2005;71:432-438

4 Santos KT, Fernandes JC, Amorim RB, Bevilacqua MC. Avaliação da Percepção da fala no ruído em diferentes posições em adultos com Implante Coclear. Int Arch Otorhinolaryngol 2009;13:16-23

5 Souza IPS, Brito R, Bento RF, Gomez MV, Tsuji RK, Hausen-Pinna M. Percepção de fala em adolescentes com surdez pré-lingual usuários de implante coclear. Braz J Otorhinolaryngol 2011;77:153-157

6 Moore BC. The role of temporal fine structure processing in pitch perception, masking, and speech perception for normal-hearing and hearing-impaired people. J Assoc Res Otolaryngol 2008;9(4): 399-406

7 Rizzi FML, Bevilacqua MC. Efeitos do número e localização dos eletrodos na cóclea na percepção da fala de indivíduos póslinguais implantados. Braz J Otorhinolaryngol 2003; 69:364-369

8 Riss D, Arnoldner C, Reiss S, Baumgartner WD, Hamzavi JS. 1-year results using the Opus speech processor with the fine structure speech coding strategy. Acta Otolaryngol 2008;3:1-4

9 Ribeiro CF. Introdução ao Implante Coclear. In: Frota S. Fundamentos em Fonoaudiologia. 2nd ed. Rio de Janeiro, Brazil: Guanabara Koogan; 2003:195-210

10 Mello TM. Percepção da fala em crianças usuárias de implante coclear com 2 estratégias de processamento de sinal do sistema HIResolution [dissertation]. São Paulo, Brazil: Faculdade de Medicina da Universidade de São Paulo; 2012

11 Lacerda AP. Audiologia Clínica. Rio de Janeiro, Brazil: Guanabara Koogan; 1976

12 Valente SLO. Elaboração de listas de sentenças construídas na língua portuguesa [dissertation]. São Paulo, Brazil: Pontifícia Universidade Católica; 1998

13 Cox RM, Alexander GC. The abbreviated profile of hearing aid benefit. Ear Hear 1995;16(2):176-186

14 Cary NC. SAS Institute Inc. SAS/STAT® User's Guide, Version 9. SAS Institute Inc. California, USA; 1999 
15 Willott JF. Physiological plasticity in the auditory system and its possible relevance to hearing aid use, deprivation effects, and acclimatization. Ear Hear 1996;17(3, Suppl):66S-77S

16 Humes LE, Wilson DL, Barlow NN, Garner C. Changes in hearing-aid benefit following 1 or 2 years of hearing-aid use by older adults. J Speech Lang Hear Res 2002;45(4): 772-782

17 Tremblay K. Central auditory plasticity: implications for auditory rehabilitation. Hearing J 2002;56:10

18 Palmer CV. Deprivation and acclimatization in the human auditory system: do they happen? Do they matter?. Hearing J 1999; 52:23-24

19 Carvalho CN. Implante coclear no sul do Brasil: Realidade ou fantasia? [dissertation]. São Paulo, Brazil: Cefac; 1999

20 Guedes MC, Weber R, Gomez MV, Neto SG, Peralta CG, Bento RF. Efeitos do potencial de ação neural sobre a percepção de fala em usuários de implante coclear. Braz J Otorhinolaryngol 2007; 73:439-445
21 Kutscher K, Goffi-gomez V, Befi-lopes DM, Tsuji RK, Bento RF. Implante coclear: correlação da recuperação neural, privação auditiva e etiologia. Pró-Fono Rev At Ci 2010;22:473-478

22 Seebens Y, Diller G. Improvements in speech perception after the upgrade from the TEMPO+ to the OPUS 2 audio processor. ORL J Otorhinolaryngol Relat Spec 2012;74(1):6-11

23 Calháu CMDF, Lima Júnior LR, Reis AMCS, et al. Perfil etiológico dos pacientes implantados do Programa de Implante Coclear. Braz J Otorhinolaryngol 2011;77(1):13-18

24 Bevilacqua MC, Costa AO, Moret ALM. Implante coclear em criança. In: Campos $\mathrm{CAH}$, Costa HOO. Tratado de Otorrinolaringologia da Sociedade Brasileira de Otorrinolaringologia. São Paulo, Brazil: Roca; 2003:268-77

25 Porto CPR. Avaliação de resultados de implante coclear em pacientes deficientes auditivos secundário à meningite [dissertation]. Campinas, Brazil: Universidade de Campinas; 2001

26 Lima LI, Aiello CP, Ferrari DV. Correlações audiométricas do Questionário de Handicap Auditivo para Adultos. Rev CEFAC 2011; 13:496-503 